\title{
A AGENDA LEGISLATIVA DO GOVERNO CASTELO BRANCO: UM REGIME POLÍTICO EM TRANSIÇÃO
}

\section{CASTELO BRANCO'S LEGISLATIVE AGENDA: A POLITICAL REGIME IN TRANSITION}

Ricardo de João Braga*

Resumo: O Golpe Militar de 1964 configurou uma ruptura política geral para o país e uma mudança específica para o Poder Legislativo federal. O governo Castelo Branco, contudo, apresenta características próprias, que o diferem das configurações democráticas anteriores e dos governos posteriores de Costa e Silva e Médici. O artigo utiliza metodologia quantitativa e usa fontes primárias e secundárias. Ele analisa e descreve a agenda legislativa do governo Castelo Branco, categoriza as propostas legislativas do Poder Executivo de acordo com temas, resultados e tempo de apreciação pelo Legislativo. Também é analisado o impacto das novas regras legislativas impostas pelos militares e procede-se a uma comparação dos achados com o período democrático imediatamente anterior. Os resultados mostram que o Poder Executivo teve uma agenda reformista, principalmente nas áreas econômica e de administração pública, e que alcançou uma taxa de sucesso significativa para suas propostas. Ademais, contudo, viu-se que o Poder Legislativo conseguiu ainda atuar de forma relevante em diversas proposições, que foram rejeitadas ou alteradas de modo a ensejar vetos do Poder Executivo. Constatou-se também que as novas regras legislativas impostas pelos militares foram muito importantes para aumentar a taxa de sucesso da agenda do Executivo e influenciaram o tempo de apreciação das propostas pelo Legislativo.

Palavras-Chave: Poder Legislativo; Golpe militar de 1964; Comportamento legislativo;

Processo legislativo.

Abstract: The military coup d'etat Brazil lived in 1964 was a great break in national political regime, and an important change for the National Legislature. Castelo Branco's government is, however, a different situation from the previous democratic period and the later military

\footnotetext{
* Doutor em Ciência Política pelo Instituto de Estudos Sociais e Políticos IESP da Universidade do Estado do Rio de Janeiro em 2011, mestre em Ciência Política pela UnB, 2006. Atualmente é professor no Centro de Formação, Treinamento e Aperfeiçoamento CEFOR da Câmara dos Deputados, atuando em seu curso de Mestrado em Poder Legislativo, cursos de especialização e cursos livres (ricardo.braga@ camara.leg.br).
} 
governments of Generals Costa e Silva and Médici. This article uses quantitative techniques, primary and secondary sources. It analyzes and describes the legislative agenda initiated by the Executive Branch, and categorizes Executive draft bills according subject, results, and the time spent by the Legislature to appreciate them. It also assess the impact of the new legislative rules imposed by the militaries and compares its findings with the previous democratic situation. Findings show that the Executive Branch had a reformer legislative agenda, specially at economic and public administration areas, and it reached a high success score for its proposals. Besides, findings shows that this specific Legislature was important yet, based on the number of draft bills rejected by the congressmen and the number of vetoes made by the Executive Branch. The new legislative rules imposed by the military were very important to improve the governments success score and influenced the congress examination length of time.

Keywords: Legislative Branch; 1964 brazilian coupe d’Etat; Legislative behavior; Legislative process.

\section{Introdução}

O Golpe Militar de 1964 configurou uma ruptura para o Poder Legislativo federal, com cassações de parlamentares, mudanças na dinâmica das relações Executivo-Legislativo e criação de novos instrumentos legislativos que aumentaram a capacidade de atuação do Poder Executivo dentro do Parlamento.

O primeiro termo do período ditatorial, presidido pelo Marechal Castelo Branco, contudo, apresenta características próprias, que o diferem para as questões legislativas das configurações institucionais e políticas tanto anteriores quanto posteriores. Quando comparado ao período imediatamente posterior, dos Presidentes Costa e Silva e Médici, o Congresso ainda apresentou um grau de atuação relevante, interferindo de forma significativa em matérias importantes. Pode-se afirmar também que as percepções dos parlamentares sobre o golpe militar neste período inicial ainda não anteviam a quase total anulação do Poder Legislativo que ocorreria depois. Para o Legislativo federal, o governo Castelo Branco é uma transição, um momento intermediário entre a política livre e de maior poder do Congresso na República de 46 e a anulação desta liberdade e protagonismo com a ascensão da linha dura militar ${ }^{1}$.

A fim de melhor compreender a especificidade deste momento, sem igualá-lo ao Congresso nulo que se costuma assumir para o período militar como um todo, e também para diferenciá-lo do momento democrático anterior, este trabalho, de perspectiva analíticodescritiva, tem por objetivos:

\footnotetext{
${ }^{1}$ É ilustrativo que em sua página eletrônica institucional a Câmara dos Deputados traz como periodização da $4^{\text {a }}$ República o interregno 18/09/1946 a 15/03/1967, o que é um indício de que, ao ver desta casa legislativa, o período Castelo Branco não significou uma ruptura profunda em seu funcionamento (cf. http://www2.camara.gov.br/acamara/conheca/historia/historia/a4republica.html).
} 
- identificar a agenda legislativa do Poder Executivo no governo Castelo Branco, classificando e quantificando os Projetos de Lei Ordinária - PLs de iniciativa do Presidente da República por áreas temáticas;

- analisar o padrão de tramitação das propostas do Poder Executivo, quantificando taxa de sucesso e o impacto do uso de instrumentos legislativos de exceção (os novos poderes legislativos conferidos ao Poder Executivo pelos Atos Institucionais números 1 e 2 - AI-1 e AI-2);

- comparar esses achados com o padrão de tramitação legislativa do período dos governos Jânio Quadros e João Goulart.

Utiliza-se metodologia quantitativa que categoriza e quantifica o número de proposições, em linha com trabalhos de corte neoinstitucionalista que buscam compreender as relações Executivo-Legislativo e o comportamento legislativo a partir de padrões de produção legislativa (por exemplo, FIGUEIREDO e LIMONGI, 1999; SANTOS, 2003). Para a comparação com o período dos governos Jânio Quadros e João Goulart, baseia-se em fontes secundárias, especificamente o trabalho de Wanderley Guilherme dos Santos (1986).

Os resultados apontam que o Poder Executivo possuía uma agenda de caráter reformista nas áreas econômicas e administrativa e que obteve alta taxa de sucesso. Verifica-se ainda que as novas regras legislativas de exceção tiveram impacto significativo no processo legislativo.

O trabalho está dividido nas seguintes seções: i) golpe militar, cassações e instrumentos legislativos de exceção; ii) agenda legislativa do Presidente da República, taxas de sucesso e prazo de tramitação; iii) Democracia liberal e governo Castelo Branco: conclusões sobre o que mudou no trâmite legislativo.

\section{Golpe militar, cassações e instrumentos legislativos de exceção}

O bloqueio legislativo a uma agenda de reformas ampla é considerado como um dos elementos do quadro político que levou ao golpe militar de 1964. Havia tanto um enfrentamento entre os poderes Executivo e Legislativo, aguçado nos governos Jânio Quadros e João Goulart, como uma clivagem interna ao Congresso, intensificada com o avanço do PTB nas eleições de 1962 e seu rompimento com o PSD, que antepunha posições conservadoras a outras reformistas ou mesmo revolucionárias (IANNI, 1978; SKIDMORE, 1976; SANTOS, 1986). O Legislativo seria uma parte no quadro de conflitos e tensões que o Brasil enfrentava ao empreender um processo intenso de modernização nas décadas precedentes (industrialização e urbanização como seus elementos motrizes).

Como mostra Santos (1986), no ano de 1963 houve um travamento no processo legislativo, constatado pelo nível de criação de normas bastante inferior aos anos antecessores. Enquanto a apresentação de projetos subiu 44\% em relação ao ano de 1962, o número de 
aprovados caiu 21\% (SANTOS, 1986, p. 47). No sentido contrário, após o golpe de 64 aumentou muito a aprovação de leis ordinárias (cf. Tab. 1).

Tabela 1 - PLs Apresentados e Aprovados no Congresso Nacional 1960 e 1966 - Variação Anual (\%)

\begin{tabular}{l|r|r}
\hline & \multicolumn{2}{|c}{1960 e 1966 - Variação Anual (\%) } \\
\hline $\mathbf{1 9 6 0}$ & $-19 \%$ & \multicolumn{2}{c}{ Aprovados } \\
\hline $\mathbf{1 9 6 1}$ & $7 \%$ & $-24 \%$ \\
\hline $\mathbf{1 9 6 2}$ & $-8 \%$ & $27 \%$ \\
\hline $\mathbf{1 9 6 3}$ & $44 \%$ & $-16 \%$ \\
\hline $\mathbf{1 9 6 4}$ & $-47 \%$ & $-21 \%$ \\
\hline $\mathbf{1 9 6 5}$ & $4 \%$ & $130 \%$ \\
\hline $\mathbf{1 9 6 6}$ & $-22 \%$ & $20 \%$ \\
\hline
\end{tabular}

Fonte: Santos (1986, p.47)

Com a tomada do poder pelos militares, a consecução de uma agenda de reformas implicaria uma dinâmica legislativa muito mais efetiva. Neste ponto deve-se considerar que uma alternativa hipotética para os militares seria simplesmente a supressão do Legislativo, algo que seria feito alguns anos depois. Não extinguir o Legislativo imediatamente ao golpe configurou uma situação específica, a qual é o grande mote ensejador desta pesquisa.

Deve-se lembrar que "uma agenda de reformas" não era exclusividade dos derrotados com o golpe. Pode-se questionar os rumos que o Brasil seguiu nos aspectos político, social e econômico, mas é indubitável que os militares impuseram mudanças profundas à sociedade e à economia brasileira, configurando uma passagem a um novo padrão fiscal, tributário e orçamentário e de relação Estado-Economia (ABREU, 1992). Como apontam analistas, o governo militar buscou legitimar-se por meio dos avanços econômicos, sua bandeira estratégica (CARDOSO, 1972).

Pode-se afirmar, para o governo Castelo Branco, que houve importantes mudanças em políticas públicas e no status quo jurídico, ocorridas, neste primeiro termo ditatorial, sem a supressão do Poder Legislativo. Como exemplos: a reestruturação monetária do país, com a criação institucional do Banco Central - BACEN e do Conselho Monetário Nacional - CMN; uma nova política monetária; uma nova política fiscal - com o controle orçamentário e o financiamento público com títulos com correção monetária (ORTN) -; a criação do Sistema Financeiro da Habitação; uma nova regulamentação para o Mercado de Capitais; criação do Fundo de Garantia por Tempo de Serviço - FGTS; e, com um caráter também social, a aprovação do Estatuto da Terra. 
A existência de uma dinâmica política significativa no Legislativo durante o governo Castelo, principalmente até a dissolução do multipartidarismo, pode ser constatada por alguns fatos:

1) a alta rotatividade de ministros com vistas a conseguir apoio parlamentar. Santos (1986, p. 117 e 123) aponta que as indicações ministeriais no período Castelo continuaram altas (37 ministros), pouco superior ao período democrático anterior - com exceção do número extremamente alto do governo Goulart (60) -, e bastante superior aos presidentes militares que o sucederam (COSTA E SILVA, 19, e MÉDICI, 20). Seu objetivo seria conseguir apoio político ao governo.

2) O número de CPIs implementadas no governo Castelo, em níveis superiores ao período democrático anterior (a média mensal de propostas foi de 1,90 de abril de 1964 a janeiro de 1966, bastante superior ao nível da República de 46, de 0,77 - ainda, neste período Castelo foram concluídas 87\% das CPIs (FIGUEIREDO, 2001, p. 698)). CPIs são ações que chamam atenção para o Legislativo e colocam em suas mãos decisões políticas relevantes. Nesta mesma obra Figueiredo (2001) afirma que Castelo Branco foi apoiado por uma coalizão de partidos.

3) A difundida percepção que o golpe militar não instalaria um regime ditatorial permanente. Isto pode ser visto, após o golpe, nas pretensões presidenciais mantidas em importantes atores políticos como Juscelino Kubitschek , Carlos Lacerda e Ademar de Barros, que foram se dissipando à medida que o regime permanecia e ações políticas, como os Atos Institucionais, tornavam-se mais drásticas.

Como entende Skidmore (1976), num primeiro momento lideranças políticas acreditavam que a intervenção militar seguiria o padrão anterior da República, em que os militares atuaram como árbitros das disputas políticas, tomando o poder em momentos de crise e devolvendo-o às elites civis posteriormente. Nesse sentido, é reconhecido também que Castelo Branco não assumiu o comando militar com um projeto de manutenção do poder de longo prazo, como viria a ocorrer com a ascensão da "linha-dura" (VIANNA, 1987, p. 104-5). Pelo contrário, Castelo apresentava-se mais como um governo temporário, e como aponta Gaspari (2002), se não fosse sua morte em acidente aéreo logo após deixar o poder, trabalharia para a superação do governo militar.

4) A própria trajetória de recrudescimento dos atos políticos, exemplificada pelo crescendo dos Atos Institucionais, provam que os militares adotaram uma estratégia de asfixia crescente do mundo político, e não uma ação radical imediata ao golpe.

Uma primeira possível explicação para o sucesso legislativo do governo Castelo Branco assenta-se na política de cassações de parlamentares. Foram cassados, no momento imediato do 
golpe, por meio do Ato do Comando Supremo da Revolução n ${ }^{\circ} 2^{2}$, de 10 de abril de 1964, 36 deputados em exercício (AZEVEDO, RABAT, 2012, 28-30). Segundo Azevedo e Rabat, foram cassados, ao longo da Legislatura 1963-1967, 67 deputados, sendo 61 ao longo de 1964 (abril a junho) e seis no ano de 1966 (outubro) (2012, 57-95). Foram cassados pela ditadura também oito senadores, sendo Juscelino Kubitschek em 1964 e o restante em legislaturas posteriores (BRASIL, 2012) ${ }^{3}$.

Como mostra Gláucio Soares, "a política de cassação" tinha um objetivo razoavelmente claro, extirpar os membros da Frente Parlamentar Nacionalista - FPN (SOARES, 1979). A Frente defendia uma política de autonomia econômica e política, de nacionalismo e participação popular. Soares procedeu a uma pesquisa junto a membros da FPN para definir sua composição e teve como resultado a identificação de três grupos de parlamentares: os componentes assíduos e atuantes da FPN; seus apoiadores periféricos; e os outros parlamentares não relacionados à FPN. Segundo o autor, 21 dos 22 membros assíduos foram cassados imediatamente (o último seria cassado em 1969), assim como metade dos periféricos. Quanto ao grupo não integrante da FPN, apenas um em cada sete foi cassado. Mostra também o autor que os membros assíduos da FPN e metade dos periféricos foram cassados logo em 1964, enquanto apenas $29 \%$ dos cassados não membros perderam o mandato em 1964. Como diz Soares, ser membro da FPN ou ser próximo a ela aumentava a chance de ser cassado e de ser cassado cedo (SOARES, 1979, p. 74$5)$.

Os cassados, e mesmo os membros da FPN, não estavam inseridos exclusivamente em partidos de esquerda (PSB e PTB). Embora houvesse uma concentração no PTB, houve parlamentares cassados em diversas legendas, inclusive PSD e UDN.

Os dados de Azevedo e Rabat (2012) e de Soares (1979) não são totalmente congruentes, não permitem montar um quadro exato da composição do Congresso após as cassações. Em alguns casos são computadas cassações de suplentes e membros da FPN que não tinham mandato na Legislatura 1963-1967. Também não é possível rastrear agora quantas e quais foram as posses decorrentes destas cassações. Contudo, os números permitem compor um quadro geral e subsidiam inferências e análises.

Um primeiro efeito hipotético das cassações é quantitativo e estático, podendo ser analisado sob a perspectiva da teoria política formal e da ideia de eleitor mediano (HINICH, MUNGER, 1997). Subtraíram-se do Legislativo em 1964 cerca de 15\% do total do colegiado (houve 409 vagas em disputa para a Câmara dos Deputados em 1962 e 61 cassações em 1964),

\footnotetext{
${ }^{2}$ O AI 1 previa a possibilidade de cassações: “Art. 10. No interesse da paz e da honra nacional, e sem as limitações previstas na Constituição, os Comandantes-em-Chefe, que editam o presente Ato, poderão suspender os direitos políticos pelo prazo de dez (10) anos e cassar mandatos legislativos federais, estaduais e municipais, excluída a apreciação judicial desses atos." Interessante, ou sintomático, como o AI 1 fala de mandatos legislativos, e não mandatos políticos em gênero.

${ }^{3}$ Os dados provêm de sessão solene do Senado Federal para devolução de mandatos cassados, realizado em 20 de dezembro de 2012. Azevedo e Rabat (2012) referem-se à cassação do Senador Amauri Silva, não identificado no material citado do Senado Federal como cassado.
} 
cassado um contingente majoritariamente de esquerda. Em termos do eleitor mediano, ter-se-ia um deslocamento em direção à direita do espectro partidário (isto sem considerar a posição ideológica dos suplentes que assumiram mandatos, que poderiam também ser de esquerda e diminuir o efeito das cassações sobre a posição do eleitor mediano). Nesta visão apenas quantitativa da composição do colegiado, parlamentares presentes no Legislativo antes e depois do golpe (não cassados e não suplentes) não alterariam sua linha de voto. Neste raciocínio hipotético o parlamentar seria cassado ou não, mas fora isso não sofreria influência do contexto e não alteraria seu comportamento pré-golpe.

Dentro desta perspectiva hipotética, ter-se-ia que encontrar oscilações de resultado de votação em pequenas margens, resultados que passariam de uma margem apertada no contexto pré-golpe, a também margens apertadas, na direção oposta, no contexto pós-golpe (entendendose que apenas $15 \%$ dos eleitores poderiam mudar seu voto). Contudo, como veremos adiante, não se viu este tipo de mudança no comportamento do colegiado. Houve de fato a alteração entre uma pauta "travada" no pré-golpe e outra que fluía sem obstáculos, em geral, no pósgolpe.

Esta visão acima relatada, que se pode chamar de "visão estática do eleitor mediano", considera que as preferências e as atitudes dos parlamentares mantiveram-se as mesmas. Apenas pela mudança dos componentes do colegiado, cassação de uns e posse de outros, os resultados finais alterar-se-iam. Contudo, há um segundo efeito potencial das cassações a ser considerado.

As cassações poderiam ter constrangido os parlamentares remanescentes, impelindo-os para uma atitude mais pró-governo do que na situação pré-golpe. Neste caso estar-se-ia falando em submissão à pauta do Poder Executivo. Conforme argumento de Morgenstern (2002), um Legislativo pode ser submisso ao Executivo por depender dele para sua sobrevivência política, troca-se qualquer pretensão em política pública (a substância das decisões sobre proposições legislativas) por ganhos de outras naturezas. É o que o autor classifica como Congresso "subserviente".

Embora este efeito submissão não possa e não deva ser descartado no estágio atual da pesquisa, parece um pouco exagerada a ideia de que um Congresso pré-golpe com dinâmica relativamente independente e diversos conflitos tanto internos quanto com o Executivo passasse imediatamente a uma condição de homogeneidade submissa. Embora, como se verá, muitas votações tiveram desfecho rápido e favorável ao Executivo, houve também derrotas. Além disso, o número de CPIs e a rotatividade dos ministros, como apontado acima, são indícios de que a política ainda contava com atores relevantes no Legislativo. Neste sentido, duas explicações concorrentes devem ser consideradas, e uma delas será desenvolvida neste artigo.

Uma primeira explicação para o "destravamento" da agenda legislativa está na construção de um novo contexto de relações Executivo-Legislativo no que se refere às possibilidades de políticas públicas, tanto ao seu tipo quanto ao risco de sua implementação. 
Esta possibilidade foi analisada em outra oportunidade (BRAGA, 2011) por meio de estudo de caso da criação do BACEN e do CMN. A tese lá desenvolvida permite compreender que o contexto do início dos anos 1960 havia tornado a opção por políticas públicas paroquialistas e distributivistas - possíveis por iniciativa do Legislativo (SANTOS, 2003) - praticamente disfuncional. Políticas desta natureza enfrentavam alto risco de não cumprimento, mesmo se aprovadas pelo Legislativo, e isto pela incapacidade orçamentária do governo, desequilíbrio que se articulava à inflação e constituía a "economia política" da República de 46. Com o novo quadro político pós-golpe, a reputação do presidente e de seus principais formuladores de políticas (por exemplo, Roberto Campos e Octávio G. de Bulhões) e a agenda que ia se encorpando e demonstrando realizações apontavam para a possibilidade crível de implementação de determinados tipos de políticas públicas. Como é reconhecido, a legitimidade buscada pelo governo militar assentava-se na proposta e na execução de uma boa administração econômica (CARDOSO, 1972; FERNANDES, 1975).

No caso referido da criação do BACEN e do CMN (BRAGA, 2011), ao contrário de políticas paroquialistas e distributivistas conseguidas no varejo, um dos elementos centrais para o sucesso da pretensão do Poder Executivo foi a barganha com o Legislativo em cima da institucionalização da política de crédito rural, um ganho importante para diversos parlamentares, mas feito de forma ampla e geral. Em outros trabalhos se seguirá por esta via explicativa, mas aqui desenvolver-se-á outra, a da importância dos novos instrumentos legislativos disponíveis ao Poder Executivo pelo golpe.

A literatura sobre o Congresso Brasileiro atual (FIGUEIREDO e LIMONGI, 1999; SANTOS, 2003), ao lado da distribuição de cargos à base de apoio parlamentar, enfatiza a importância de instrumentos legislativos postos à disposição do Executivo. Instrumentos como Medidas Provisórias e pedidos de urgência servem para gerar coordenação entre os atores, impulsionando pautas de interesse do Poder Executivo. Tais instrumentos são peças constituintes do "poder de agenda" conferido ao governo.

A origem de tais instrumentos legislativos disponíveis ao Executivo encontra-se neste exato período militar, onde se constituíram, em momentos diversos, o controle do Executivo sobre o Orçamento, a aprovação por decurso de prazo e os decretos-lei ${ }^{4}$. Com modificações ao longo de sua história, o que se vê é uma evolução destes institutos, importantes para o controle da agenda de trabalhos legislativos, e que se mantém ainda hoje.

Os principais instrumentos legislativos postos à disposição do Poder Executivo pelo golpe são apresentados no Quadro 1 abaixo.

\footnotetext{
${ }^{4}$ A história política brasileira anterior conheceu alguns destes instrumentos, ou variações, contudo, os instrumentos referidos no Quadro 1 não existiam na República de 46 e são instituídos pelo governo militar. Conferir a obra de Júlio Roberto de Souza Pinto (2009) sobre a evolução histórica dos institutos legislativos brasileiros.
} 
Quadro 1 - Instrumentos Legislativos do Poder Executivo criados no governo Castelo Branco

\begin{tabular}{|c|c|c|}
\hline Instrumento & Conteúdo & Criação \\
\hline $\begin{array}{l}\text { Rito para Proposta de } \\
\text { Emenda à Constituição - } \\
\text { PEC apresentada pelo } \\
\text { Presidente da República }\end{array}$ & $\begin{array}{l}\text { PEC } \\
\text { - Presidente da República passa a ter } \\
\text { iniciativa (antes era vedada); } \\
\text { - prazo para apreciação de } 30 \text { dias (para } \\
\text { outros postulantes não há prazo); } \\
\text { - apreciação conjunta da Câmara dos } \\
\text { Deputados e Senado Federal (para } \\
\text { outros postulantes, apreciação } \\
\text { separada); } \\
\text { - aprovação por maioria absoluta (para } \\
\text { outros proponentes, maioria de } 2 / 3 \text { ). }\end{array}$ & $\begin{array}{l}\text { AI 1, de } 9 \text { de abril de } \\
1964\end{array}$ \\
\hline $\begin{array}{l}\text { Aprovação por decurso de } \\
\text { prazo para PLs do Presidente } \\
\text { da República }\end{array}$ & $\begin{array}{l}\text { - projetos de autoria do Presidente da } \\
\text { República serão apreciados em até } 30 \\
\text { dias pela Câmara dos Deputados e } \\
\text { mesmo prazo para o Senado Federal; } \\
\text { - a não apreciação no prazo implica } \\
\text { aprovação; } \\
\text { - Executivo pode pedir apreciação } \\
\text { urgente em } 30 \text { dias, em sessão conjunta } \\
\text { das casas. }\end{array}$ & $\begin{array}{l}\text { AI 1, de } 9 \text { de abril de } \\
1964\end{array}$ \\
\hline $\begin{array}{l}\text { Vedação à criação de despesa } \\
\text { pelo Congresso }\end{array}$ & $\begin{array}{l}\text { - Só PLs de autoria do Poder Executivo } \\
\text { podem propor criação ou aumento de } \\
\text { despesa; } \\
\text { - É vedada ao Legislativo apresentação } \\
\text { de emendas que aumentem despesas. }\end{array}$ & $\begin{array}{l}\text { AI 1, de } 9 \text { de abril de } \\
1964\end{array}$ \\
\hline $\begin{array}{l}\text { Aprovação por decurso de } \\
\text { prazo para PLs do Presidente } \\
\text { da República - II }\end{array}$ & $\begin{array}{l}\text { - PLs de Iniciativa do Presidente da } \\
\text { República: prazo de } 45 \text { dias na Câmara } \\
\text { dos Deputados, } 45 \text { dias no Senado } \\
\text { Federal e } 10 \text { dias para apreciação de } \\
\text { emendas do SF (tramitação começa pela } \\
\text { Câmara dos Deputados); } \\
\text { - não apreciação em qualquer fase } \\
\text { implica aprovação. }\end{array}$ & $\begin{array}{l}\text { Ato Institucional } \mathrm{n}^{\circ} 2 \text {, } \\
\text { de } 27 \text { de outubro de } \\
1965 \text {. Posteriormente } \\
\text { presente na Emenda } \\
\text { Constitucional } \mathrm{n}^{\circ} \quad 17 \\
\text { de } 1965 \text {, de } 26 \text { de } \\
\text { novembro. }\end{array}$ \\
\hline
\end{tabular}

Fonte: Elaborado pelo autor a partir da legislação brasileira.

A pesquisa empírica desenvolvida neste trabalho tem um objetivo restrito, focado na tramitação dos PLs de autoria do Presidente da República. Busca-se identificar a agenda do Executivo, que em boa medida é operacionalizada por Leis Ordinárias, identificar sua taxa de sucesso e prazos de tramitação, e compreender os padrões encontrados. Como se verá, os instrumentos de exceção têm importância significativa neste quadro.

\section{Agenda legislativa do presidente da república, taxas de sucesso e prazo de tramitação}

\subsection{Nota Metodológica}

Esta seção analisa a pauta legislativa do governo Castelo Branco. O universo de análise é limitado aos PLs de autoria do Poder Executivo, os quais são classificados por área temática, taxa de sucesso e tempo de tramitação. Como apresentado na seção anterior, o objetivo é avaliar 
o impacto dos instrumentos legislativos de exceção conferidos ao Presidente da República especificamente em relação aos PLs.

Os PLs foram escolhidos como objeto de análise pelas seguintes razões: i) são a proposição de autoria do Poder Executivo mais abundante, o que permite uma maior amostra da relação Executivo-Legislativo no processo legislativo; ii) são objeto de novos instrumentos legislativos conferidos ao Executivo pela quebra do regime democrático; iii) são as proposições também analisadas por Santos (1986), o que permite comparações.

Os dados foram levantados a partir do sítio eletrônico da Câmara dos Deputados, filtrados pelo autor Poder Executivo, e limitados àqueles iniciados entre $1^{\circ}$ de abril de 1964 e 31 de dezembro de 1966. Contou-se também com a ajuda específica do Centro de Documentação e Informação da Câmara dos Deputados - $\mathrm{CEDI}^{5}$.

Para o período, os dados apresentam algumas inconsistências. Atualmente os registros de tramitação são alimentados de forma imediata e direta no sistema eletrônico de controle, o que diminui a imprecisão e aumenta os dados disponíveis. Para a época pesquisada, o sistema foi alimentado a posteriori, a partir dos processos em papel, também digitalizados e disponíveis para conferência. Os maiores problemas de registro verificados referem-se às datas de apresentação e finalização da tramitação, por inconsistências de registro. Em diversos casos foi verificada a autenticidade desses dados por meio da análise dos "avulsos", que são os processos físicos das proposições digitalizados e disponibilizados na página da Câmara dos Deputados.

Em relação às datas de apresentação e finalização da tramitação, ou foram tomadas as datas presentes no sistema ou aquelas dos avulsos. Referem-se respectivamente ao momento inicial de tramitação do projeto (que, inconsistentemente, oscila entre a data do documento de apresentação do projeto pelo Poder Executivo e a data do primeiro despacho na CD) e ao final (que pode ser o dia da sanção, da publicação no DOU ou do arquivamento, da rejeição ou retirada do projeto).

Outra limitação à análise das datas deu-se pela imprecisão na definição dos momentos de recesso parlamentar, quando não devem correr os prazos legais para apreciação obrigatória de proposições. Os prazos ordinários de funcionamento do Congresso encontram-se na Constituição Federal, mas podem ocorrer convocações extraordinárias. Consulta a obras de compilação (BRASIL, 1992) e registros nos diários da Câmara dos Deputados foram incoerentes, e por isso não permitiram registro e desconto desses períodos - carecendo de pesquisa posterior. Ao não desconsiderar os períodos de recesso, a pesquisa insere um viés no sentido de dificultar a prova da hipótese aqui trabalhada - que o período de tramitação tornou-se mais rápido. Como foram encontrados períodos de tramitação bastante acelerados, mesmo sem

\footnotetext{
${ }^{5}$ Ao qual agora se aproveita para agradecer publicamente.
} 
o desconto dos recessos, vê-se que o viés é mais uma garantia de que os achados são consistentes.

\subsection{Resultados:}

O universo de análise compõe-se de 566 PLs, apresentados entre $1^{\circ}$ de abril de 1964 e 31 de dezembro de 1966.

Tabela 2 - PLs por resultado legislativo

\begin{tabular}{cccccccc}
\hline Total & Leis & $\begin{array}{l}\text { Leis - } \\
\text { Veto } \\
\text { Parcial }\end{array}$ & $\begin{array}{l}\text { Veto } \\
\text { Total }\end{array}$ & Rejeitados & Prejudicados & Arquivados & Retirados \\
\hline $\mathbf{5 6 6}$ & 479 & 40 & 2 & 13 & 1 & 3 & 28 \\
\hline $\mathbf{1 0 0 , 0 \%}$ & $84,6 \%$ & $7,1 \%$ & $0,4 \%$ & $2,3 \%$ & $0,2 \%$ & $0,5 \%$ & $4,9 \%$ \\
\hline
\end{tabular}

Fonte: Elaborado pelo autor com dados disponíveis no sítio eletrônico da Câmara dos Deputados www.camara.leg.br

A Tabela 2 mostra o resultado dos PLs encaminhados pelo Poder Executivo ao Legislativo. De um total de 566 PLs, 479 (84,6\%) foram aprovados sem sofrer vetos, enquanto $55(9,7 \%)$ foram aprovados com veto parcial ou total ou foram rejeitados. Por fim, 28 (4,9\%) foram retirados e apenas quatro $(0,7 \%)$ foram prejudicados ou arquivados.

A interpretação destes dados, relativa a quem "determina" os resultados legislativos, gera controvérsias, e muitas vezes não responde às indagações mais informativas. Há dois problemas básicos. O primeiro é a lei das reações antecipadas (FRIEDRICH, 1963). Pode-se argumentar, em termos lógicos, que um projeto de autoria do Poder Executivo foi aprovado no Legislativo por ter, a priori, se ajustado às preferências do colegiado. Tem-se a soma do interesse do Executivo, que toma a iniciativa (porque se não tivesse interesse não teria iniciativa), e a do Legislativo, que tem suas preferências respeitadas e por isso aprova a proposta. Assim, em termos hipotéticos, não haveria uma submissão ou ajuste do Legislativo ao Executivo, mas sim uma cooperação entre os poderes. É certo que esta argumentação tem que ser qualificada à luz do contexto político mais amplo, mas mostra a fragilidade em se tomar iniciativa e resultados legislativos de forma acrítica.

O outro problema reside na temporalidade. Aprovações, rejeições, vetos e retiradas ocorrem dentro de um processo dinâmico, em que as posições iniciais dos atores podem se modificar alimentadas por fatores endógenos e exógenos ao processo legislativo, e assim os resultados finais, embora algumas vezes aparentemente contraditórios com os objetivos iniciais, são consistentes com o interesse dos atores.

Tais considerações sobre a análise de iniciativas e resultados legislativos faz com que se veja com uma boa dose de ceticismo muitas interpretações sobre prevalência de um ou outro poder. O que parece é que, em termos teórico-metodológicos, muitas vezes tem-se o problema 
da "equivalência observacional" (LOEWENBERG, SQUIRE, KIEWET, 2002), em que teorias concorrentes preveem as mesmas ocorrências empíricas e, a partir dessas ocorrências, não se pode determinar qual teoria é mais aderente à realidade. Diante de prescrições idênticas, a escolha por uma ou outra teoria assenta-se sobre frágeis fundamentos, devendo-se procurar outras variáveis e prescrições capazes de prover um julgamento mais seguro.

Considerados esses "perigos" interpretativos, pode-se avançar alguns elementos que alimentem a discussão das relações Executivo-Legislativo naquela quadra histórica: o Legislativo do governo Castelo Branco estava totalmente submisso, suprimido do processo legislativo? A resposta considera as precauções da "equivalência observacional". Não é possível atestar que a interpretação A ou B esteja certa apenas com base nos resultados legislativos. Poder-se-ia argumentar que uma rejeição de $100 \%$ aos projetos do Executivo mostraria um Legislativo que impusesse suas preferências, mas ainda assim dever-se-ia controlar esse resultado por outros eventos legislativos, como a aprovação de outros projetos, que mesmo de iniciativa de parlamentares, poderiam estar alinhados aos interesses do Executivo. A lição aprendida é que os resultados legislativos sozinhos não bastam, e que se considere qual a questão a ser respondida. Neste artigo, o achado que se busca é discernir se o Legislativo do governo Castelo Branco era já meramente um carimbador (rubber stamp) ou ainda detinha importância política.

A resposta encontrada baseia-se nos resultados legislativos, em que 55 PLs (9,7\% do total) tiveram resultados diversos do pretendido pelo Poder Executivo (assumida a hipótese que o Executivo quisesse uma aprovação sem vetos), e também nas razões políticas de ordem mais ampla apontadas anteriormente, relativas à rotatividade dos Ministros e ao número de $\mathrm{CPIs}^{6}$ no período. Entende-se que o Legislativo era ainda um ator político relevante, embora com um processo legislativo diferente daquele anterior ao golpe.

A abertura desses resultados legislativos por tema, em que alguns mais polêmicos tiveram resultados diversificados, também ajuda a embasar a resposta aqui oferecida.

Tabela 3 - PLs por Tema

\begin{tabular}{|c|c|c|}
\hline Tema & Observações & Frequência \% \\
\hline Orçamento & 221 & $39,0 \%$ \\
\hline Administração & 141 & $24,9 \%$ \\
\hline Tributário & 77 & $13,6 \%$ \\
\hline Previdência & 22 & $3,9 \%$ \\
\hline Economia & 20 & $3,5 \%$ \\
\hline Finanças Públicas & 19 & $3,4 \%$ \\
\hline Outros & 66 & $11,7 \%$ \\
\hline Total & 566 & $100,0 \%$ \\
\hline
\end{tabular}

\footnotetext{
${ }^{6}$ A lógica das reações antecipadas permitiria pensar também que alguns dos projetos aprovados sem veto possam ter sido "modulados" aos interesses legislativos antes do envio. Mas isso é apenas uma hipótese não passível de teste pelo método deste artigo.
} 
Fonte: Elaborado pelo autor com dados disponíveis no sítio eletrônico da Câmara dos Deputados www.camara.leg.br

Em relação às áreas temáticas dos PLs, há grande concentração nas matérias econômicas e de administração do Estado. As três primeiras categorias, Orçamento, Administração e Tributário contam com 439 PLs, 77,5\% do total. A sexta categoria em quantidade, Finanças Públicas, com mais 19 PLs, também se enquadra na administração do Estado, elevando esta temática ampla a 80,9\% do total (mais de 4 projetos em 5 apresentados).

A categoria Orçamento refere-se a projetos que abrem e transferem créditos e à própria lei orçamentária anual. Administração a questões de pessoal, patrimônio da União e estrutura e competências de órgãos públicos. Tributário, por sua vez, indica isenções de tributos para empreendimentos específicos, mas também algumas regras tributárias mais gerais. Já a categoria Finanças Públicas refere-se a fundos públicos, transferências de bens, operações de crédito e investimentos públicos ${ }^{7}$.

A concentração de PLs indica a importância da agenda de reformas econômicas para o governo e também a própria lógica da atividade governativa nos Estados modernos, em que muitas ações exigem a prescrição por lei - "governa-se por meio de leis".

Tabela 4 - Resultados legislativos por tema dos PLs.

\begin{tabular}{|c|c|c|c|c|c|c|c|c|}
\hline & Orçamento & Administração & Tributação & Previdência & Economia & $\begin{array}{c}\text { Finanças } \\
\text { Públicas }\end{array}$ & Outros & Total \\
\hline Lei & 208 & 113 & 68 & 20 & 13 & 13 & 44 & 479 \\
\hline $\begin{array}{c}\text { Veto } \\
\text { Parcial }\end{array}$ & 2 & 13 & 6 & 1 & 7 & 3 & 8 & 40 \\
\hline Veto Total & 1 & 1 & & & & & 1 & 2 \\
\hline Rejeitado & 1 & 5 & 1 & & & 1 & 5 & 13 \\
\hline $\begin{array}{c}\text { Retirado } \\
\text { pelo autor }\end{array}$ & 8 & 8 & 2 & 1 & & 7 & 28 \\
\hline Arquivado & 2 & 1 & & & & & & 3 \\
\hline Prejudicado & & 141 & 77 & 22 & 20 & 19 & 66 & 566 \\
\hline TOTAL & 221 & & & & & & & \\
\hline
\end{tabular}

Fonte: Elaborado pelo autor com dados disponíveis no sítio eletrônico da Câmara dos Deputados www.camara.leg.br

As Tabelas 4 e 5 apresentam os resultados legislativos por tema dos PLs e corroboram análises anteriores. Em primeiro lugar, vê-se que os projetos orçamentários tiveram grande percentual de aprovações sem contestação. Os projetos de orçamento são, em sua larga maioria, abertura de créditos para ações previamente definidas, levantamento de meios para atingimento de fins definidos em outras esferas e momentos. De um total de 221 proposições, 208 foram

\footnotetext{
${ }^{7}$ A categoria Previdência refere-se quase exclusivamente a proposições que conferiram aposentadorias e pensões a indivíduos específicos (leis para um beneficiário). A categoria Economia referiu-se a regulação econômica, fomento e tarifas e taxas (que talvez pudessem ser também colocados dentro da categoria tributário). Já a categoria Outros traz algumas matérias de áreas importantes para políticas públicas, como agricultura, minas e energia, meio ambiente, trabalho, transportes, assim como alterações em Direito Penal e Civil. Além delas, inclui também leis para regulamentação de profissões, questões políticas (como o Código Eleitoral), leis simbólicas e outras que não foi possível classificar.
} 
aprovadas sem veto. Acrescente-se a isso que oito projetos foram retirados, mas que na iniciativa de retirada o Poder Executivo alegava já ter conseguido resolver a questão de recursos por outras vias legais. Isto é, o governo não "precisou" aprovar o projeto.

Em matérias como Administração e Economia vê-se que o dissenso foi mais usual: 113 aprovados sem veto em um total de $141(80,1 \%)$ no primeiro caso, e 13 em 20 no segundo caso (65\%) (cf. Tab. 5). A interpretação que se dá a esses casos é que, em matérias mais estruturais, quando muitas vezes se decide o mérito de ações governamentais, o debate e a construção conjunta de soluções foram mais presente. $\mathrm{O}$ dissenso em algumas matérias, como as descritas neste parágrafo, mostra um Poder Legislativo mais atuante.

Tabela 5 - Resultados legislativos por tema dos PLs, \%

\begin{tabular}{|c|c|c|c|c|c|c|c|c|}
\hline & Orçamento & Administração & Tributação & Previdência & Economia & $\begin{array}{c}\text { Finanças } \\
\text { Públicas }\end{array}$ & Outros & Total \\
\hline Lei & $94,1 \%$ & $80,1 \%$ & $88,3 \%$ & $90,9 \%$ & $65,0 \%$ & $68,4 \%$ & $66,7 \%$ & $84,6 \%$ \\
\hline $\begin{array}{c}\text { Veto } \\
\text { Parcial }\end{array}$ & $0,9 \%$ & $9,2 \%$ & $7,8 \%$ & $4,5 \%$ & $35,0 \%$ & $15,8 \%$ & $12,1 \%$ & $7,1 \%$ \\
\hline Veto Total & $0,0 \%$ & $0,7 \%$ & $0,0 \%$ & $0,0 \%$ & $0,0 \%$ & $0,0 \%$ & $1,5 \%$ & $0,4 \%$ \\
\hline Rejeitado & $0,5 \%$ & $3,5 \%$ & $1,3 \%$ & $0,0 \%$ & $0,0 \%$ & $5,3 \%$ & $7,6 \%$ & $2,3 \%$ \\
\hline $\begin{array}{c}\text { Retirado } \\
\text { pelo autor }\end{array}$ & $3,6 \%$ & $5,7 \%$ & $2,6 \%$ & $4,5 \%$ & $0,0 \%$ & $10,5 \%$ & $10,6 \%$ & $4,9 \%$ \\
\hline Arquivado & $0,9 \%$ & $0,7 \%$ & $0,0 \%$ & $0,0 \%$ & $0,0 \%$ & $0,0 \%$ & $0,0 \%$ & $0,5 \%$ \\
\hline Prejudicado & $0,0 \%$ & $0,0 \%$ & $0,0 \%$ & $0,0 \%$ & $0,0 \%$ & $0,0 \%$ & $1,5 \%$ & $0,2 \%$ \\
\hline TOTAL & $100,0 \%$ & $100,0 \%$ & $100,0 \%$ & $100,0 \%$ & $100,0 \%$ & $100,0 \%$ & $100,0 \%$ & $100,0 \%$ \\
\hline
\end{tabular}

Fonte: Elaborado pelo autor com dados disponíveis no sítio eletrônico da Câmara dos Deputados www.camara.leg.br

A partir dos resultados legislativos, sobretudo considerados por área temática, defendese aqui que ainda houve atividade política relevante no Legislativo no período do Presidente Castelo Branco (corroboradas por elementos como número de CPIs e rotatividade de Ministros, referidos anteriormente). O que se fará adiante é analisar o papel do novo instrumento legislativo conferido ao Poder Executivo, a aprovação por decurso de prazo.

Como mostram Figueiredo e Limongi (1999), grande parte da dificuldade do processo legislativo consiste em esforços de ação coletiva. Analisou-se uma amostra dos processos dos PLs objeto desta pesquisa e comprovou-se que foram encaminhados pelo Presidente da República dentro das regras da aprovação por decurso de prazo (cf. Quadro 1$)^{8}$. Desta forma, o ônus da ação coletiva recaía sobre o Congresso, que deveria se organizar e votar um projeto em tempo hábil se desejasse rejeitá-lo ou oferecer-lhe modificações. Se o Legislativo desejasse a aprovação do projeto sem alterações poderia não se movimentar. E se o colegiado não conseguisse se organizar, prevaleceria o desejo do Poder Executivo, que poderia proclamar a aprovação do PL original quando expirasse o prazo.

\footnotetext{
${ }^{8}$ Há mesmo um questionamento de natureza jurídica se o Poder Executivo poderia abrir mão destes prazos restritos, enviando a matéria sob outro regramento ou ignorando os próprios decursos de prazo. Salvo melhor juízo, estas opções parecem vedadas.
} 
O decurso de prazo, conforme as regras instituídas pelo AI 1, exigiam que os PLs fossem aprovados em 60 dias pelo Congresso (30 dias em cada casa). Poderia haver sessão conjunta e prazo menor, de 30 dias, caso o Presidente da República pedisse urgência ao projeto. Com o AI 2 e a Emenda Constitucional no 17, já no final de 1965, o prazo para apreciação de PLs do Executivo elevou-se para 100 dias (45 na Câmara dos Deputados, 45 no Senado Federal e 10 dias para apreciação de emendas do Senado Federal pela Câmara dos Deputados, se fosse o caso), à exceção da urgência, que concede apenas 30 dias de prazo ao Congresso. Tais prazos não contavam durante os períodos de recesso parlamentar.

Consolidados por ano ou também por tema (Tabs. 6 e 7), o que se vê nos PLs aprovados sem veto é que os prazos médios, assim como as medianas, oscilaram entre um mínimo de 57 dias e um máximo de 94 dias entre a apresentação do projeto e sua sanção, o que mostra o enquadramento, em geral, nas novas regras excepcionais de apreciação. Ademais, no cômputo destes prazos deve-se considerar que não houve o desconto do recesso parlamentar, o que traria todas estas medidas para valores menores. Além disso, a sanção pelo Presidente agrega dias à contagem realizada - período computado nas tabelas (prazo final é, em geral, a sanção) - mas não se insere no prazo concedido para apreciação, que corre apenas até o Congresso fazer sua manifestação final.

Considerados os valores encontrados para o tempo de tramitação, os descontos que deveriam ser dados pelos recessos e o tempo que o processo ficou à disposição do Presidente da República para sanção, constata-se que na grande maioria dos casos a imposição de prazos pelo presidente foi efetiva. Devido à metodologia de pesquisa aqui utilizada e às limitações de registro dos dados, não se pode afirmar que todos os projetos que se tornaram lei sem vetos foram aprovados pelo Legislativo, pois é possível que muitos não tenham sido apreciados no período regulamentar e assim foram aprovados por decurso de prazo $^{9}$. Nesse sentido, conclui-se que os prazos são efetivos para o Poder Executivo promulgar a lei, mas não necessariamente conseguir o assentimento do Legislativo.

Tabela 6 - PLs apreciados, por ano, e tempo de tramitação dos aprovados sem veto (dias corridos)

\begin{tabular}{|c|c|c|c|c|c|}
\hline & & & \multicolumn{3}{|c|}{$\begin{array}{r}\text { Transformados em Lei (sem vetos) - Dias } \\
\text { de Tramitação }\end{array}$} \\
\hline Ano & N $^{\text {o }}$ PLs & $\begin{array}{c}\text { Transformados em } \\
\text { Lei (Sem Vetos) }\end{array}$ & Média & Mediana & $3^{\circ}$ Quartil (75\% abaixo) \\
\hline $\mathbf{1 9 6 4}$ & 134 & 103 & 76 & 57 & 65 \\
\hline $\mathbf{1 9 6 5}$ & 226 & 198 & 65 & 62 & 71 \\
\hline $\mathbf{1 9 6 6}$ & 206 & 178 & 88 & 85 & 105 \\
\hline Total & 566 & & & & \\
\hline
\end{tabular}

Fonte: Elaborado pelo autor com dados disponíveis no sítio eletrônico da Câmara dos Deputados www.camara.leg.br

\footnotetext{
${ }^{9}$ Uma amostragem assistemática, preliminar, mostra que muitos projetos foram, de fato, aprovados no prazo.
} 
Tabela 7 - PLs apreciados, por tema, e tempo de tramitação dos aprovados sem veto (dias corridos)

\begin{tabular}{|c|c|c|c|c|c|}
\hline & & & \multicolumn{3}{|c|}{ Transformados em Lei (sem vetos) - } \\
Dias de Tramitação
\end{tabular}

Fonte: Elaborado pelo autor com dados disponíveis no sítio eletrônico da Câmara dos Deputados www.camara.leg.br

Adicionalmente é interessante analisar o tempo de tramitação dos 55 projetos que foram aprovados com vetos parciais, que sofreram veto total ou foram rejeitados.

Tabela 8 - $\mathrm{N}^{\mathrm{o}}$ de PLs aprovados com veto parcial, veto total ou rejeitados e tempo de tramitação (dias corridos)

\begin{tabular}{|c|c|c|c|}
\hline & \multicolumn{3}{|c|}{ Dias de Tramitação } \\
\hline PLs & Média & Mediana & $\begin{array}{c}3^{\circ} \text { Quartil } \\
(75 \% \text { abaixo })\end{array}$ \\
\hline $\mathbf{5 5}$ & 87 & 72 & 101,5 \\
\hline
\end{tabular}

Fonte: Elaborado pelo autor com dados disponíveis no sítio eletrônico da Câmara dos deputados www.camara.leg.br

Para 55 PLs (9,7\% do total) do Poder Executivo encaminhados entre abril de 1964 e dezembro de 1966 o Congresso conseguiu organizar-se coletivamente para deliberar e oferecer modificações ou rejeitar a proposição. Nestes 55 casos a média e a mediana do tempo de tramitação são similares àqueles encontrados para os PLs aprovados sem veto ${ }^{10}$. Considera-se aqui que este esforço de alterar ou rejeitar praticamente $10 \%$ das propostas do Executivo neste tempo exíguo de tramitação foi uma prova de vitalidade do Congresso, capaz de dar algumas respostas significativas ao Executivo na interação que se estabeleceu entre ambos ${ }^{11}$.

\footnotetext{
${ }^{10}$ Como já se disse anteriormente, os projetos transformados em lei sem vetos podem nem mesmo terem sido apreciados pelo Congresso, mas sim de lá retirados e sancionados após o decurso de prazo que era prerrogativa do Poder Executivo. Rejeitar ou alterar um projeto só pode ocorrer respeitando o prazo constitucional, que se impunha como uma ameaça ao Congresso, um risco caso ele não conseguisse organizar-se para atuar como desejava.

${ }^{11}$ Os achados preliminares apontam que o Senado Federal foi o grande responsável pelas rejeições. Quanto às alterações que ensejaram vetos, não foi possível ainda fazer seu rastreamento.
} 


\section{Democracia liberal e governo castelo branco: o que mudou no trâmite legislativo}

O trabalho de Santos (1986) demonstra o grau de paralisia que sofreu o Poder Legislativo no momento anterior ao golpe. Assistiu-se a um travamento da pauta, relacionado ao número de partidos presentes no Congresso e à polarização ideológica que se estabeleceu entre eles, mais aguda nos momentos finais do período democrático, quando se rompeu a antiga aliança PTB-PSD.

O governo Castelo Branco, contudo, conheceu um Congresso que em geral aprovou suas propostas, viabilizando a construção de um novo modelo de governo e de relações EstadoSociedade. Razões de sobrevivência política e um modificado contexto para políticas públicas podem ter influenciado a nova dinâmica legislativa. Além disso, as novas regras de aprovação por decurso de prazo - o que este artigo procurou identificar e analisar - tiveram impacto, um elemento estritamente institucional.

Afora demonstrar o contraste entre o período democrático da República de 46 e o primeiro governo militar, pôde-se também verificar que o Legislativo teve um comportamento similar em todos os três primeiros anos pós-golpe, quando prazos e taxas de aprovação não variaram significativamente no tempo e mesmo entre os PLs controlados por tema.

O que se chamou no título do artigo de "um regime político em transição" faz referência ao processo de anulação do Legislativo ao longo do período militar. Nos governos seguintes, com bipartidarismo, eleições cada vez mais controladas, fechamento do Congresso, mais cassações e recrudescimento do clima de autoritarismo político, assiste-se a uma virtual anulação do Legislativo brasileiro como ator político relevante ou decisivo de políticas públicas. Autores que se debruçaram sobre o período militar como um todo veem o poder concentrar-se no Executivo, num modelo de face tecnocrática (por exemplo, VIANNA, 1987; CODATO, 1997), e analistas preocupados especificamente com o Legislativo, como Polsby, em artigo de 1975 (p. 264) descartam qualquer participação política relevante do Poder Legislativo brasileiro na produção de normas (talvez influenciado pelo contexto imediato que conhecia, do período Médici).

Este artigo procura qualificar este debate ao lançar luz sobre o processo de transição, pois a anulação do Legislativo não se deu de imediato ou com uma só medida autoritária. Como se procurou demonstrar, há indicativos de uma ação política significativa do Congresso no governo Castelo Branco. Mapeados os projetos de iniciativa do Poder Executivo, constata-se que o Legislativo conseguiu se organizar para produzir ações legislativas relevantes, vistas em rejeições congressuais a projetos ou promoção de vetos do Executivo.

Ademais, os novos instrumentos legislativos disponíveis ao Poder Executivo pelo golpe tiveram um papel importante em formatar o novo padrão de tramitação legislativa ao acelerar processos e ceder o protagonismo das iniciativas ao Presidente da República. 
Por se tratar de um trabalho inserido numa agenda de pesquisa mais ampla sobre o Legislativo e as mudanças econômicas e políticas no governo Castelo Branco, ele enseja algumas discussões de alcance mais largo. Uma pretensão teórica a ser desenvolvida diz respeito à compreensão dos Legislativos não apenas em períodos de estabilidade democrática, quanto também como este poder comporta-se em momentos de transição, seja de democratização seja de fechamento rumo à autocracia (LINZ, STEPAN, 1978; 1999).

Outra linha de avanço é teórico-metodológica, referente a modelos interpretativos e sua operacionalização. Muitos estudos legislativos apoiam-se apenas em variáveis endógenas a este poder, como iniciativa de proposição, taxa de sucesso, tempo de tramitação. Aqui se vê que estas ocorrências empíricas podem ter variados sentidos e interpretações. A compreensão da importância do Legislativo e mesmo de sua dinâmica exige que se considere o contexto mais amplo, no qual ele é apenas um "subsistema", e que se construa metodologia que leve em conta outras variáveis passíveis de análise.

\section{Referências}

ABREU, M. P. (org.). A Ordem do Progresso: cem anos de política econômica republicana, 1889-1989. Rio de Janeiro, Campus. $4^{\text {a }}$ ed. 1992.

AZEVEDO, D.; RABAT, M. N. Parlamento mutilado: deputados federais cassados pela ditadura de 1964. Brasília: Câmara dos Deputados, Edições Câmara, 2012.

BRAGA, R. de J. O Processo Decisório Legislativo na Criação e Reforma do Bacen e do CMN em 1964 e 1994: Incerteza, Cooperação e Resultados Legislativos. Tese de Doutorado. IESP/UERJ, 2011.

BRASIL. CONGRESSO. CÂMARA DOS DEPUTADOS. Cronologia do funcionamento da Câmara dos Deputados: 1826-1992. Brasília: Câmara dos Deputados, Coordenação de Publicações, 1992.

. SENADO FEDERAL. Ata da Sessão do Plenário do Senado Federal. 20/12/2012. Sessão: 239ª Deliberativa Ordinária, 2012.

CARDOSO, Fernando Henrique. O modelo político brasileiro. São Paulo: Difel, 1972. CODATO, Adriano Nervo. Sistema Estatal e Política Econômica no Brasil pós 64. Editora Hucitec. São Paulo, 1997.

FERNANDES, Florestan. Sociedade de classes e subdesenvolvimento. Rio de Janeiro: J. Zahar, 1975.

FIGUEIREDO, A. C. Instituições e Política no Controle do Executivo. Dados, v. 44, n. 4, p. 689-727, jan. 2001.

FIGUEIREDO, A. C.; LIMONGI, F. Executivo e Legislativo na nova ordem constitucional. Rio de Janeiro: Fundação Getúlio Vargas : Fapesp, 1999.

FRIEDRICH, Carl. Man and His Government. New York: McGraw-Hill, 1963.

GASPARI, Elio. A ditadura envergonhada. São Paulo: Companhia das Letras, 2002.

HINICH, M. J.; MUNGER, M.C. Analytical Politics. Cambridge University Press, 1997. 
IANNI, O. O colapso do populismo no Brasil. $4^{\text {a }}$ ed. Rio de Janeiro: Civilização Brasileira, 1978.

LINZ, Juan J.; STEPAN, Alfred. The Breakdown of Democratic Regimes: Europe.

Baltimore: Johns Hopkins University Press, 1978.

A Transição e consolidação da democracia: a experiencia do sul da Europa e da América do Sul. São Paulo: Paz e Terra, 1999.

LOEWENBERG, G., SQUIRE, P., KIEWET R. "The Implications of the Study of the Study U.S. Congress for Comparative Legislative Research", in Loewenberg, G., Squire, P. Kiewet R. (eds.) Legislatures. Comparative perspectives on Representative Assemblies, Ann Arbor, The University of Michigan Press, pp. 3-22, 2002.

MORGENSTERN, S. "Explaining Legislative Politics in Latin America." in MORGENSTERN, S.; NACIF, B. (ed). Legislative politics in Latin America. Cambridge; New York: Cambridge University Press, 2002.

PINTO, Júlio Roberto de Souza. Poder legislativo brasileiro: institutos e processos. Rio de Janeiro: Forense, 2009.

POLSBY, N. "Legislatures", in Greenstein, F. I., Polsby N. W. (ed) Handbook of Political Science, V. Reading-Mass.: Addison-Wesley, 1975, pp. 257-319.

SANTOS, F. O Poder Legislativo no Presidencialismo de Coalizão. Belo Horizonte, Editora UFMG. Rio de Janeiro, IUPERJ, 2003.

SANTOS, W.G. Sessenta e Quatro: Anatomia da Crise. São Paulo: Vértice, 1986.

SKIDMORE, T.E. Brasil: de Getúlio Vargas a Castelo Branco. Rio de Janeiro: Paz e Terra S.A, $5^{\text {a }}$ ed. 1976.

SOARES, G. A. D. As Políticas de Cassações. Dados, Rio de Janeiro, n. 21, p. 69 a 85, 1979.

VIANNA, M. L. T. W. A Administração do Milagre: o Conselho Monetário Nacional (1964-1974). Petrópolis: Vozes, 1987.

Artigo recebido em: 21/08/2014

Artigo aceito para publicação em: 25/08/2014 